\title{
BENEFITS DERIVED BY A MAJOR SOUTH AFRICAN RETAILER THROUGH COLLABORATION AND INNOVATION WITHIN ITS SUPPLY CHAIN
}

\author{
M.A.O. DOS SANTOS \\ mariads@uj.ac.za \\ Department of Marketing Management \\ University of Johannesburg \\ South Africa
}

\begin{abstract}
Current trends in the macro-environment, such as increased obesity within human populations, the damaging impact of human activity on the natural environment, the worldwide recession and the resultant changes in consumer behaviour, are all receiving increased attention by relevant stakeholders around the world. As the negative impact of these macro-environmental trends continue to be felt, increased pressure will be placed on the business community to help mitigate their consequences. This study demonstrates how innovation and collaboration within a retailer's supply chain enable it to profitably use some of these macro-environmental trends to create differential and competitive advantage in a saturated business sector.
\end{abstract}

\section{INTRODUCTION}

Retailers do not operate in isolation in a business environment nor do they have full control over their businesses since they are dependent on their primary and support suppliers for products and services that enable them to satisfy their target market's needs. This reliance on the members of the supply chain by retailers occurs because retailers sell products and/ or services produced by the members of the supply chain to consumers for their personal or family use (Levy \& Weitz, 2009: 7). Dudek (2009: 6) states, 'that the recognition of supply chains makes it apparent that no single company or business unit fully controls the manufacturing and distribution of its products. Instead, it is dependent on the contribution of others and the interactions between the various parties involved in the total process'. Markley and Davis (2007: 766) define a supply chain as a series of companies including suppliers, customers and logistics providers that work together to deliver a value package of goods and services to the end customer. According to Markley and Davies (2007), direct interaction with supply chain partners enables a company to react more quickly to changes in the marketplace and to respond more promptly to customer requests.

Webster (2001: 46) quotes Hogarth-Scott (1999) who identifies the following three types of retailer-supplier relationship: 
1. A partnership between the retailer and a strong branded supplier, usually the market leader. In this instance the power is equally balanced between them.

2. Own brand/private label relationship where the producer of the retailer's own brand has a very close relationship with the retailer.

3. Retailer relationships with 'secondary brand' manufacturers tend to be one of compliance where the retailer expects manufacturers to comply with their demands.

The retailer in this case study prefers to work with its suppliers to bring about change and innovation in its products. For example in its press release dated 18 March 2008, the Good Business Journey manager, who is responsible for the overall implementation of this retail chain's sustainable business, stated that this retail chain had a long history of working with suppliers to influence change and manage the environment responsibly. This retailer also has a policy of assisting emerging suppliers who add value to their supplier base. In their press release dated 30 July 2008, it was stated that 'this retailer is committed to identifying opportunities for suppliers to grow with the business. In addition to giving access to the marketplace, this retailer provides emerging suppliers with training that covers best practice in technical and business management skills, organisational development and financing where possible'. Lamming and Hampson (1996: S52) state that if a collaborative approach is used within the supply chain, in other words all the players participate and assist each other, they are able to find ways to mitigate and evaluate their impact on the natural environment. These researchers suggest that because each member of the supply chain has a vested interest in the other's success, this collaboration will ensure that the optimal solutions are found to solve the environmental impact problem and suppliers will be encouraged by the opportunities that are generated by this approach. An additional benefit to the collaborative approach according to Lamming and Hampson (1996: S52) is that standards requirements by the purchaser provide a basis for constructive dialogue with suppliers in the context of a joint commitment to quality improvement. Purchasing standards also encourage suppliers to examine the activities of their own suppliers.

\section{Macro-environmental factors as drivers of innovation}

Changes in the external macro-environment can be perceived by businesses as being either an opportunity or a threat. Businesses that scan the external environment are able to identify those changes within the macro-environment that drive them to innovate and to meet the changing needs of their target market. In this study, the changing macro-environmental trends that have provided opportunities for this retailer and its supply chain to innovate and collaborate are discussed in order to demonstrate how the macro-environment drives innovation and how the whole supply chain benefits from this proactive approach.

The natural environment is a macro-environmental factor that is attracting a great deal of attention in South Africa and around the world. Brian Joffe, CE of Bidvest Group Limited, 
is quoted by Anonymous ${ }^{1}$ (2008/9: 25-26) as saying that the world is now entering the age of the environment and businesses are faced with the real issues of global warming, diminishing natural resources and the threat of worldwide poverty. According to Brian Joffe, 'opportunities abound for protecting the environment while profiting from appropriate services and products,' while Cyril Ramaphosa in the same article supports this viewpoint by saying that 'innovation inspires creativity and inspires Bidvest people to seek opportunities in the growth area of "green" entrepreneurship.' Peattie (2001: 133) supports this business approach when he states that the search for environmentally superior solutions leads to innovation and the creation of more efficient, effective technologies and methods for resource utilisation that provide businesses with competitive advantage.

An environmental issue that is receiving increased attention in all sectors of South Africa is global warming. This issue has become topical due to its negative impact on human society, the environment and the survival of the fauna and flora on this planet. The problem with global warming is that it is associated with human activity and is the result of the burning of fossil fuels (oil, gas and coal) to generate energy for human and business consumption. Currently in South Africa, the energy and transportation sector are the biggest producers of greenhouse gases.

Bond, Dada and Erion (2007: 8) state that the energy sector in South Africa alone contributes $87 \%$ of the carbon dioxide, $96 \%$ of the sulphur dioxide and $94 \%$ of the nitrous oxide released by this country. Since most of the energy supplied to business and consumers in South Africa is derived from the combustion of coal, this suggests that the users of electricity in this country are also contributing to the greenhouse gas problem since they provide a market for this sector. The other significant contributor to South Africa's greenhouse gas emissions, namely the transport industry, currently releases more than 10000 metric tons of greenhouse gas into the atmosphere yearly (Bond et al., 2007: 9). Anonymous ${ }^{1}$ (2008/2009: 26) quotes Cyril Ramaphosa, non-Executive chairman of Bidvest Group Limited, who states that 'some $60 \%$ of the world's crude oil production accounts for $14 \%$ of global greenhouse gas emissions.'

In a statement issued by The Presidency in 2009, prior to the Copenhagen summit on climate change, the following comments were made:

South Africa being a responsible global citizen and in line with its obligations under article 4.1 of the United Nations Framework Convention on Climate Change acknowledges its responsibility to undertake national action that will contribute to the global effort to reduce greenhouse gas emissions. In accordance with this, South Africa will undertake mitigation actions which will result in a deviation below the current emission baseline of around 34\% by 2020 and by around $42 \%$ by 2025 . This level of effort enables South African to peak between 2020 and 2025, plateau for approximately a decade before a decline in absolute terms thereafter. 
South Africa's proposed reduction of greenhouse gas emissions was made with the proviso that certain conditions were met. Even though the outcomes of the Copenhagen summit were unsatisfactory, the statements made by The Presidency demonstrate that South Africa acknowledges its responsibility to assist in the mitigation of greenhouse gas emissions and it also indicates to some extent what South Africa needs do in order to reduce its greenhouse gas emissions. Currently the South African government has provided support for the following initiatives aimed at reducing the amount of greenhouse gases released into the atmosphere (statement by The Presidency, 2009):

- $100 \mathrm{MW}$ utility scale wind power generation plant

- $100 \mathrm{MW}$ concentrated solar power plant

- Conversion of electrical water heating to solar water heating in 1 million households

- Scaling up of energy-efficient projects as leveraged for commercial and industrial sectors.

The South African government is serious about the mitigation of greenhouse gases and this significant since South Africa is Africa's largest contributor to greenhouse gas emissions. Currently South Africa emits $42 \%$ of the continent's carbon dioxide emissions (Bond et al., 2007: 10) and it is anticipated that South Africa will continue to introduce legislation that protects the environment and encourages businesses to reduce their impact on global warming and climate change. Harris (2009: 48) states that the South African government is serious about environmental issues, and non-compliance by companies regarding environmental law is costly. According to Nortje, a lawyer who specialises in safety, health and environmental law and quoted by Harris (2009: 48), the South African 'government continues to roll out new legislation that elevates and broadens the reach of environmental laws and forces businesses in South Africa to take notice'.

This case study seeks to demonstrate practically how a major South African retailer, in collaboration with its supply chain, is able to use trends in the macroenvironment and innovation to mitigate its impact on society and the natural environment while profitably creating differential and competitive advantage in a market that is fast becoming saturated. This is particularly significant when one takes into account Levy and Weitz's (2009: v) statement that retail organisations are pervasive in society and as a result they have a major impact on the welfare of their customers, suppliers, and employees. According to Levy and Weitz (2009: v), retailers are becoming more concerned about social issues facing the world such as global warming, immigration, health care, and working conditions in less developed countries. In order to address these issues, retailers are focusing their attention on green products, global sourcing and sustainable issues in store operations and design (Levy \& Weitz, 2009: v). 
The current mass media attention and political debate on global warming is contributing to an increased awareness among consumers about this issue and its impact on the environment and on human populations. Moroke (2009: 3) for example states that people have become aware of the fact that irresponsible private and public consumption is detrimental to everybody. He further states that there is an emerging trend in the marketplace where consumers believe that what is good for the pocket needs to be good for the planet. This becomes particularly significant as countries such as the United States openly accept the fact that global warming does impact negatively on human health (SABC 3, 8 December 2009, 19:00) and reports such as the one produced by Holland (2008: 4) state that intervention studies have shown that particulate matter, sulphur dioxide and nitrogen oxide released from the combustion of coal into the atmosphere have been linked to higher death rates and increased hospital admissions associated with respiratory and cardiac illnesses. Spence (2005: 64) states that in addition to the human suffering related to deaths associated with extreme events, cardiac and respiratory illnesses, a warming climate will encourage the spread of dangerous diseases such as the West Nile virus that is not easily detected and cannot be cured.

As the negative impact of global warming and climate change begins to increasingly affect human populations around the world, more attention will be drawn to this macroenvironmental variable and more pressure will be placed on governments and businesses to reduce their negative contribution to this environmental variable. According to Davies (2008: 10) one of the ways businesses can assist in reducing the impact of human activity on the environment is to have a greener supply chain. Davies (2008: 11) states that WalMart, a major American retailer, was able to achieve big returns from small changes in packaging just by partnering with its supply chain. In doing this, Wal-Mart was able to save the following in one year:

- 3425 tons of corrugated materials

- 1358 barrels of oil

- 5190 trees

- 727 shipping containers

- US\$3.5 million in transportation costs.

Another advantage associated with a 'greener' supply chain according to Markley and Davis (2007: 763-64) is that of competitive advantage in the marketplace. Markley and Davis (2007: 767) quote an Environmental Protection Agency report that states that many US businesses have 'significantly increased their competitiveness by engaging in such environmental performance activities as:

- reducing the obsolesce and waste associated with maintenance, repair and operating materials through enhanced purchasing and inventory management practices 
- substantially reducing costs due to scrap and material losses

- lowering training, material handling, and other expenses for hazardous materials through more timely and accurate materials tracking and reporting systems

- decreasing the use and waste of solvent paints, and other chemicals through chemical service partnerships

- recovering valuable materials and assets with efficient product take back systems.'

Markley and Davis (2007: 768) go on to state that the logistics function of the supply chain also plays a significant role in the implementation of any environmental strategy. These researchers quote the work of the Ford Motor Company which was able to introduce recyclable plastic containers to ship its parts around the world. The outcomes of this strategy were:

- The product was more sustainable in that fewer trees were cut to ship the parts since corrugated board was no longer used to ship product.

- The containers were more resilient and larger so they could carry more parts. This reduced the total number of shipments which in turn reduced the amount of greenhouse gases produced by their inter-modal transportation system.

- Once the containers could no longer be used for the transportation of parts these were ground up and used to manufacture plastic parts for cars such as mud guards.

The logistics function within the supply chain brings up another macro-environmental variable that is of major concern. This is the world's diminishing oil reserves and the high price of oil. Shiva (2008: 1) states that the unprecedented increase in oil prices during 2008 is a sign that the world is reaching or is a few years off from the highest possible level of oil production. If this is in fact true, Shiva goes on to say that oil production will have to decrease and oil prices will consequently increase. According to Shiva (2008: 1) the global warming crisis in conjunction with the foreseen oil crisis will lead to a third crisis, that of a lack of food availability for the poor members of society. This is particularly significant for South Africa where in a population of approximately 50 million (Whitfield, 2009: 16), 9 million people are unemployable due to a lack of education and skills (De Lange, 2009: 1), 17 million people are employed and of those 17 million, only 5 million earn enough to pay tax (Whitfield, 2009: 16). Poverty in South Africa is a major issue and one that is receiving a great deal of attention from the government, the mass media and South African society.

Another significant macro-environmental variable in the socio-cultural context which is receiving mass media attention is obesity within human populations. A study conducted in South Africa and quoted by Anonymous ${ }^{2}$ (2009: 29) states that $17 \%$ of children under the age of nine are obese or overweight. This comment is substantiated by another Anonymous ${ }^{3}$ article (2009: 57) that reports that obesity in South African children is increasing due to a 
lack of physical activity and a diet high in calories, fat, sugar, and salt while low in fibre and nutrients. Obesity according to this article elevates the risk of chronic conditions such as diabetes and high cholesterol later in life.

The current economic and financial crises facing individuals around the world is seeing South African consumers becoming more financially vulnerable than consumers in Europe and in other developed countries. A survey commissioned by FinMark Trust and developed by Unisa's Bureau for Market Research (Van Zyl, 2009: 14) reveals that more than 400000 South Africans have lost their jobs since the start of the current recession and of these, $42.2 \%$ are unable to pay their bills. This study also found that out of all the consumers experiencing financial difficulties, $64 \%$ have too much debt and $60.3 \%$ of these are spending more than they earn. These findings are supported by this retailer's financial report which states that consumers' shopping behaviour is changing and having an impact on this retail chain's sales as a result of the ongoing recession. This study will demonstrate how this retail chain uses innovation within its business practices to enhance its image in the marketplace and reduce the negative impact of the recession on their business.

Innovation is defined by Rogers (2003: 12) 'as an idea, practice or other object that is perceived as new by an individual or other unit of adoption'. According to Rogers (2003: 12) it matters little whether the idea is objectively new in terms of its introduction into the marketplace as it is the consumer's or individual's perception of newness that influences his or her behaviour. Ferrel and Hartline (2008: 118) state that the twenty-first century model of innovation tends to focus on issues such as quality control, cost cutting, and operational efficiency even though the development of new products is still an important concern. According to Ferrel and Hartline (2008: 118) innovation is more about reinventing business processes, creating new markets to meet untapped customer needs, and collaboration and integration within businesses. They go on to say that increasing competition and shorter product life cycles, as well as the threat of commoditisation of products is forcing companies to innovate. Businesses that utilise innovation to differentiate themselves from the competition are also known as product leaders, prospectors, pioneers and first movers in the literature (Mohr, Sengupta, and Slater, 2010: 62). This study demonstrates how a retail chain that is operating in a highly competitive market that is fast becoming saturated uses a variety of innovations, in different business areas, to take advantage of current macroenvironmental trends to differentiate and achieve competitive advantage.

The advantages associated with an innovation strategy include increased growth, better collaboration, a broader product mix, increased profit margins and the prevention of commoditisation of products (Ferrel \& Hartline, 2008: 118). Other benefits that can accrue from the utilisation of an innovation strategy include the establishment of entry barriers such as economies of scale, experience effects, reputational effects, technological leadership 
and buyer switching costs, as well as the setting of industry standards (Mohr, Sengupta \& Slater, 2010: 62-63). The disadvantages associated with an innovation strategy include high risk, high failure rates and high development costs (Mohr et al., 2010: 62). In this study the innovative strategies that are used by this retail chain are examined in the context of the retail chain itself and its supply chain. The reason for this approach is due to the fact that the retailer under consideration does not produce or make many of the products it sells but purchases these products for resale or for operational purposes within its businesses. Since this retailer offers a market for the suppliers of the products that it sells or uses, it is in part responsible for the negative impact that these businesses have on the natural environment and on society as a whole.

Lovens, Lovens and Hawken (2000: 11) suggest that applying whole-system thinking to the productivity of natural resources enables companies to save a great deal, and often small changes made downstream can have a major impact upstream. For example reducing the amount of wood fibre used to manufacture paper and cardboard means that fewer trees are cut and the chances of deforestation are reduced (Lovens et al., 2000: 12) Similarly if this retailer wants to innovate in order to develop more socially responsible products in response to changes in the socio-cultural environment, it needs the assistance and collaboration of its suppliers in order to do so. Pesonen (2001: 46) supports this view in that she states that the main contractor (in this instance the retail chain) in an industrial value chain very often puts pressure on other members of the supply chain to improve their products' environmental performance. Pesonen [2001: 46] goes on to say that the requirements for environmental performance are also forcing businesses to increasingly focus on what is happening upstream in terms of the impact of raw materials and components on the natural environment. This approach to environmental management according to Pesonen (2001: 45) has the added benefit of encouraging network co-operation within the value chain.

\section{PROBLEM STATEMENT AND OBJECTIVES}

The benefits derived by retailers through collaboration and innovation within the supply chain have not been widely studied. The primary objective of this study is to demonstrate the benefits derived by a major South African retailer through collaboration and innovation within its supply chain.

The secondary objectives for this study include:

- discussing some of the macro-environmental challenges in South Africa that have provided opportunities for innovation and collaboration within a retailer's supply chain

- examining innovation and its significance as a differentiator in a market that is fast becoming saturated (retailer's 2009 annual report) 
- describing some of the innovations that have occurred throughout this retailer's supply chain in order to demonstrate how it has been able to respond to changes in the macroenvironment, differentiate itself and develop competitive advantage through innovation and collaboration with its supply chain.

\section{RESEARCH STRATEGY}

A qualitative case study approach based on the content analysis of a major South African retailer's comprehensive 2008 and 2009 annual reports and their press releases during this period was used in this study. Communication with the manager of this retailer's Good Business Journey based in Cape Town was also carried out when issues raised in the annual report and press releases required further clarification. A content analysis approach was selected for this study because it was found that these documents contained a wealth of information that could benefit academics and practitioners who were interested in the variety of practical outcomes that could be achieved as a result of innovation and collaboration within retailer supply chains. The examples chosen for this case study do not reflect all the innovations that have been developed by this retailer's supply chain in response to changes in the macroenvironment; instead they reflect the diversity of innovation and collaboration found in this retailer's documents.

The themes identified in this study are based on the content of the material examined and on the insights gained from a survey of local and international journal literature, relevant textbooks and the mass media. This study examines some of the innovations that arose as a result of collaboration with both primary and support members of this retailer's supply chain and it utilises the different elements of the retail mix identified by Levy and Weitz (2009: 21) and Dunne and Lusch (2008: 53) to categorise the different innovations that have arisen as result of changes in the macroenvironment. The use of the retail mix to categorise the content of this retailer's documents also demonstrates this retail chain's multipronged approach toward its innovation strategy since changes in the macroenvironment have an impact on all areas of its business including the retail mix.

Innovation according to Mohr et al., (2010: 24) can be classified as 1) incremental versus breakthrough; 2) product versus process; 3) architectural versus component or modular innovation; 4) sustaining versus disruptive; and 5) organisational innovation that incorporates both business and marketing innovation. This case study does not classify the innovations done by this retailer and its supply chain in this manner due to the fact that it aims to demonstrate how different types of innovation within its retail mix create differential and competitive advantage. Instead this case study uses the approach of Ferrel and Hartline (2009) in identifying the different types of innovation. 
The retail mix that Levy and Weitz (2009: 21) and Dunne and Lusch (2008: 53) suggest is used by retailers to identify the decision variables that need to be considered in order to satisfy customer needs and influence their purchase decisions include the following:

- Customer service - which includes the set of activities and programmes undertaken by retailers to make the shopping experience more rewarding for their customers (Dunne \& Lusch, 2008: 393; Levy \&Weitz, 2009: 539). Retailers use customer service to differentiate their offerings, build customer loyalty and develop sustainable competitive advantage by providing information about the retailer's products and making it easy for customers to locate and purchase their products (Levy \& Weitz, 2009: 540).

- Store design and display - which focuses on creating a store environment that encourages the consumer to enter the store, helps customers locate merchandise easily, spend time in the store and enjoy the experience while making unplanned impulse purchases (Dunne \& Lusch, 2008: 432-433; Levy \& Weitz, 2009: 509). The retailer also uses store design to reinforce its strategy by meeting the needs of the target market and offering sustainable competitive advantage (Levy \& Weitz, 2009: 538).

- Retail communication mix - which consists of a number of elements namely advertising, sales promotions, store atmosphere, websites and community-building. These are used by retailers to build appealing brand images and to attract customers to the retail chain and its Internet sites (Dunne \& Lusch, 2008: 353). The retail communication mix is also used to encourage customers to purchase merchandise at the retailer's outlets on a continuous basis, to inform the consumer about the retailer, the merchandise and services it offers as well as to build customer loyalty (Levy \& Weitz, 2009: 441).

- Location - which is the geographical placement of a retail outlet in a specific region or area (Dunne \& Lusch, 2008: 52; Levy \& Weitz, 2009: 218) in order to serve a specific target market by maximising system profitability and minimising sales cannibalisation between locations (Levy \& Weitz, 2009: 218). Location can also be used to develop sustainable competitive advantage by offering convenient locations that are easily accessible and visible, and which may be close to activity centres such as shopping centres, hotels and entertainment, or office complexes (Levy \& Weitz, 2009: 217).

- Merchandise assortments or Merchandise as proposed by Dunne and Lusch (2008: 53) - which refers to the product mix within the retail outlet that is targeted at satisfying customer needs. According to Levy and Weitz (2009: 21) the issues that need to be considered under merchandise assortment include how much and what types of product to buy, which vendors to use and their purchase terms.

- Pricing - decisions about which are particularly significant in retailing since today's consumers are well informed and they have a variety of alternatives to choose from (Levy \& Weitz, 2009: 413). In setting the price for their merchandise, retailers need to examine four issues that play a significant role in the setting of price. These four issues include 1) the price sensitivity of the consumer that in times of economic difficulty tend to increase; 2 ) the costs associated with the products and services provided to the consumer; 3 ) the 
direct and indirect competitors' activities; and 4) the legal issues relating to pricing. For example the Competition Board in South Africa has informed this retail chain that it will be 'investigating the pro-competitive and anti-competitive effects of certain retail practices that are perceived to have a negative impact on food prices. The Competition Board will not be investigating price fixing issues as such'.

This particular retailer was chosen for this study due to the fact that their annual turnover in 2009 was R21.2 billion and their profit before tax was R1.8 billion. There are 250 corporate and 160 franchise stores in this chain giving them a total trading space of $28926 \mathrm{~m}^{2}$. The reputation of this retail chain as an innovator is well known in the marketplace as demonstrated by the fact that it has won a number of awards which include the National Business Initiative (NBI) Special Award for top performance in energy efficiency on 21 November 2008. It was also rated first in the South African leg of the Carbon Disclosure Project and it was awarded the Metropolitan Oliver Empowerment Award for being the top empowered company in 2009 in the retail and property sector. This retailer was also a finalist in the International Responsible Retailer Awards in 2009. It currently employs approximately 18000 people and operates in Africa, the Middle East, Australia and New Zealand.

\section{DISCUSSION}

An examination of this retail chain's 2008 and 2009 annual reports and its press releases for this period revealed the following in relation to its use of innovation and collaborative relationships within itself and its supply chain.

\section{Customer service}

In response to health concerns expressed by this retail chain's customers, the chain has embarked on a number of initiatives in their Good Food Journey and in collaboration with their suppliers that are targeted at providing customers with healthier food options. For example this chain has removed additives such as tartrazine and MSG from its food products, has reduced the amount of sugar in its fruit nectars and fruit juices and it has reduced the amount of salt in its breads, cereals and cold meats. It has also removed hydrogenated vegetable oils and artificial sweeteners from its food products.

In order to provide its on-line shopping customers with a highly reliable delivery service that facilitates the selection of delivery within a two-hour slot on a particular day, this retail chain uses a network of mini entrepreneurs, co-ordinated by an independent logistics company, to perform this function. The results of this process innovation have indicated that these mini entrepreneurs are able to develop close working relationships with their regular customers and in so doing sustain their businesses over time. 
According to the Good Business Journey manager of this retail chain, the chain's target market is concerned about the wellbeing of the planet and they want to recycle their waste. In order to facilitate this process, this retailer - in partnership with a well-known South African petroleum company and a well-known packaging company - is piloting a project that makes it easier for the South African consumers in the Western Cape to recycle their waste using this petroleum company's services stations. The aim of this project is to make it convenient for the consumer to recycle their waste while they are refuelling or while they are on their way to work, home or dropping the children at school. This pilot project partnership benefits all three companies in that it encourages consumers to shop at this retailer as a result of its environmentally sensitive practices, it encourages these consumers to fill their petrol tanks at the petroleum company's service stations by making it convenient for them to recycle their waste and do the two things at the same time, and it facilitates the packaging company's collection of recycled waste by increasing its volumes at the collection points. An added benefit of this pilot project is that it enables these partners to differentiate themselves from their competitors by showing their commitment to the natural environment and the planet. The results of this trial project will determine the national expansion of this programme.

\section{Store design and display}

In line with this retail chain's strategic commitment to sustainability, this retailer is using recyclable board for its in-store signage and displays. At the time of its press release in March 2008, over 30\% of the retail chain's signage was made from renewable raw materials that contained recycled fibres from post-industrial and post-consumer waste. Manufacturing board from partially recycled fibres requires less water and energy than would be used to produce a board made from virgin material, it also produces less pollutants, and it reduces the amount of waste material entering landfills. According to the décor production manager, this retail chain is committed to working with its suppliers in the printing industry in order to find innovative advancements to reduce this chain's ecological footprint.

An interesting initiative that this retail chain has undertaken with its suppliers in order to reduce its ecological footprint has been to pilot a refrigeration system within one of its Midrand stores that uses carbon dioxide as a refrigerant instead of using the hydrochlorofluorocarbons. Although both are greenhouse gases, the hydrochlorofluorocarbons (at very low concentrations) are far more efficient than carbon dioxide at trapping heat in the atmosphere and they also deplete the ozone layer. The new refrigeration system according to initial trial results appears to have the added advantage of using less energy. If this pilot project continues to be successful, it will be installed in all new stores that this retail chain opens and refurbishes in the future. 


\section{Retail communication mix}

In relation to its communication mix, this retail chain and its suppliers take full advantage of their innovations and collaborations by publicising their activities in the mass media. For example in their press release dated 20 October 2009, this retailer in conjunction with its pilot waste recycling partners explained their collaboration and its benefits to the South African community. By informing the South African consumer of their activities through the mass media, these three companies are positioning themselves in the marketplace as being innovative and socially responsible and in so doing differentiating themselves from their competitors.

\section{Location}

One of this retail chain's core values is to do business profitably in an environmentally sustainable manner in order to protect the planet's ecosystems and its people. To reduce its negative impact on the environment, this retail chain evaluates its real estate opportunities in relation to its level of eco-friendliness and its ability to facilitate the efficient use of water and water waste. This is particularly significant in South Africa where the average rainfall per annum is less than $500 \mathrm{~mm}$. According to this retailer's 2008 annual report, it was able to reduce its municipal water consumption at Head Office by $13 \%$ and its water usage in its stores by $5 \%$, while its Midrand distribution centre only uses municipal water for drinking purposes. This retail chain is committed to continually reducing it relative water consumption and it has set a target of $30 \%$ reduction by 2012 . Not only does this retailer try to reduce its own water consumption but it works with its suppliers to encourage them to also reduce their water consumption and to improve their waste water management. In order to assist its suppliers in meeting its objectives, this retail chain also works with international specialist organisations to analyse agricultural water usage in South Africa and to develop methods for its reduction in agricultural irrigation. This is important in South Africa where the agricultural sector consumes just over $50 \%$ of South Africa's water supply (retailer's 2008 annual report).

This retail chain also reduces its carbon footprint by reducing its electricity and fuel consumption. To be more effective in terms of its distribution and in order to avoid transport duplication, this retail chain develops strategic distribution centres such as their Midrand facility which saves them $9370 \mathrm{~km}$ of delivery-related travel per week and it also assists their suppliers to reduce their delivery distances to this retailer's warehouse. According to Bamford (2001: 96), suppliers who deliver directly to the retailer's own dedicated regional distribution centre accrue certain important benefits namely:

- efficient consumer response (ECR), with improved stock availability

- better and more efficient use of warehouse space

- reduced distribution costs

- supplier discounts for bulk deliveries. 
Electricity consumption by this retail chain is minimised through a number of initiatives that include:

- using automated light-switching equipment and energy-efficient light fittings in all its stores and buildings

- monitoring the electrical profiles of its various stores and other buildings to ensure that lighting and air conditioning units are managed efficiently

- conducting awareness programmes to educate its staff on the efficient use of energy

- carrying out trials on new, more efficient refrigeration systems that could be installed in-store provided they meet the required specifications.

\section{Merchandise assortments}

The retail chain being discussed is known in the marketplace for the organically produced products that it sells in-store, as well as for its sustainable marketing and retailing practices. For example, this retail chain sells clothing made from certified $100 \%$ organically produced cotton and, according to its 2008 annual report, it is the third largest consumer of this raw material in the world. In order to be able to source this raw material locally, this retail chain has been spearheading initiatives with NGOs, its supply chain partners and governmental organisations to foster the growth of the local organic cotton industry. This retail chain is able to do this since it is able to provide a formal and profitable market for the end product that is produced by the supply chain. In the summer of 2008 , the first commercial scale trial crop of organic cotton was initiated.

Organically produced cotton is not the only organically produced fibre that is used in their clothing as they also purchase clothing for resale that contains hemp, soya, organic linen, bamboo and woollen fibre. The sale of organic content clothing is a significant contributor to their overall sales and according to their 2008 annual report, sales for these products exceeded R1 billion. Organic farming benefits the environment by reducing the amount of nitrous oxide that is released into the atmosphere by artificial fertilisers; by not polluting the environment with synthetic pesticides that are not biodegradable; and by enhancing the characteristics of the soil thereby making it more healthy.

This retail chain not only sells clothing made from organically grown fibre but it also sells a wide range of organically certified foods such as organically grown vegetables, free-range animal products and independently certified organic grocery lines such as breakfast cereals, pasta, nuts, juices and so on. According to this retailer's 2008 annual report, this retail chain plans to increase the sale of its organic and free range food to over R1 billion per annum.

\section{Pricing}

According to the chairman of this retail chain, 2009 was characterised by a recession in South Africa, rising unemployment and a lack of monetary liquidity. In the first quarter of 
2009, South Africa's GDP had shrunk by $6.4 \%$ while consumer spending had dropped by $4.9 \%$ and the demand for credit by consumers had also decreased. In response to this economic environment, this retail chain's customers changed their purchase behaviour by trading down in terms of this retailer's product offerings or by patronising this retailer's competitors who were seen to offer better price propositions.

In order to promote an image of competitive food prices among its customers and to minimise its market share losses in its grocery lines, this retailer reduced its prices on 245 food lines and it introduced special promotions such as 'Meal Deal - eat in for under R100.00' while continuing to maintain its quality standards. This retail chain also aggressively managed their 63 known value items $(\mathrm{KVI})$ in such a way that they were competitively priced and were differentiated from their competitors through the maintenance and use of quality and innovation. Feedback from customers as a result of these innovations indicated that this retailer's food prices were seen to have become more competitive. In addition, as a result of this strategy, this retail chain was able to slow down its customers' patronage of its competitors.

Investments in new stock management systems by this retailer enabled it to control costs, and manage product margins and inventory more effectively. This is illustrated by the fact that during 2009, there was a shift in inventory-holding towards low-risk, all-year-round merchandise that required higher levels of availability to satisfy existing customer demand. In addition to the changes made in the type of inventory-holding practised by this retailer, the information obtained from the new stock management systems enabled the retailer to develop more appropriate store catalogues and profiles that were better suited to the needs of their target market.

\section{CONCLUSIONS}

An interesting finding in this study is the fact that this retail chain, in collaboration with its suppliers, has been able to use innovation in all aspects of its business to respond to changes in the macroenvironment and to differentiate itself from its competitors in a market that is fast becoming saturated. According to its top executives, this business has been able to use the Good Business Journey which focuses on sustainability, to differentiate itself from its competitors through innovation. By focusing on sustainability and incorporating it as a core value, it has been able to enhance its brand image and use the opportunities presented by its sustainability focus to drive efficiencies and cost savings within the business. This is a particularly significant finding since often businesses see sustainability and in particular environmental sustainability as a cost and not a profit-bearing opportunity. An additional benefit that this retail chain derives from its innovation strategy is that it creates excitement in-store and by so doing encourages repeat patronage and loyalty. 
Another interesting feature of this study is the fact that this retail chain is able to develop collaborative relationships and partnerships with its supply chain in order to meet the challenges it faces as a result of a changing macro-environment and its focus on sustainability. Its ability to do this is particularly significant since it does not manufacture products apart from the food it sells in its in-store cafés. For the members of this retailer's supply chain to participate in these innovative initiatives, they need to perceive certain benefits for themselves and this may include a profitable market for their products, cost savings and increased efficiencies similar to those perceived by the retailer, reduced risk associated with the innovations since they are guaranteed a market and a possible expansion of their market in terms of supplying other interested parties with a similar product. For example this retailer worked with its trolley and shopping basket supplier to increase the amount of recycled plastic in their products. This supplier is now offering the same type of product to other retailers around the world (2008 annual report). Other benefits that may accrue to members of this retailer's supply chain may include an enhanced image in the marketplace as a result of the implemented sustainable strategies required by the retailer under discussion, less risk associated with environmental legislation, and innovative culture within the business and its associated partnerships.

In addition to its collaborative relationships with its supply chain, this retail chain develops partnerships with other stakeholders such as governmental and non-governmental institutions that assist it in achieving its strategic objectives. An example that clearly illustrates this is the retail chain's commitment to spearheading the growth and production of organic cotton in South Africa in conjunction with the relevant stakeholders 


\section{REFERENCES}

Anonymous'1. 2008/9. In People, Profit and the Environment. CEO, Titans 2008/2009: 23-27.

Anonymous². 2009. Little Chefs. Discovery Health. Summer 2009: 29-31.

Anonymous $^{3}$. 2009. Healthy Habits. Discovery Health. Spring 2009: 57.

Bamford, C. 2001. Current practice: inter-firm relationships in the food and drinks supply chain. In Eastham, J. F., Sharples, L. and Ball, S. D., (Ed) Food Supply Chain Management: Issues for the Hospitality and Retail Sectors. Great Britain: Elsevier Butterworth Heinemann.

Bond, P., Dada, R. \& Erion, E. 2007. Introduction. In Bond, P., Dada, R. \& Erion, E. (Ed) Climate Change, Carbon Trading and Civil Society, Scottsville, South Africa: University of KwaZulu-Natal Press.

Davies, J. 2008. Collaboration's role in eco-effective supply chain. Supplier Chain Management Review, April, 2008: 10-11.

De Lange, J. 2009. Skills development standstill. FINWEEK, 6th August 2009:1 Dudek, G. 2009. Collaborative Planning in Supply Chains. Second Edition, Germany: Springer Dordrecht Heidelberg.

Dunne, P. M. \& Lusch, R. F. 2008. Retailing. 6th International Student Edition Australia: Thomson South-Western.

Ferrel, O. C. \& Hartline, M. D. 2008. Marketing Strategy, 4th Edition, Australia: Thomson, South-Western.

Harris, S. 2009. Don't wait for the Green Scorpions: comply now or go to jail. FINWEEK, 8 October 2009: 48.

Holland, M. R. 2008. The co-benefits to health of a strong EU climate change policy. From http://assets.panda.org/downloads/co benefits to health report September 2008.pdf (accessed 21 October 2008.)

Lamming, R. \& Hampson, J. 1996. The environment as a supply chain management issue. British Journal of Management, Vol.7 (Special Issue): S45-S62.

Levy, M. \& Weitz, B. A. 2009. Retailing Management, Seventh Edition, Boston: McGrawHill Irwin. 
Lovens, A. B., Lovens, H. \& Hawken, P. 2000. A road map for natural capitalism. Harvard Business Review on Business and the Environment. United States of America: Harvard Business School Press.

Markley, J. M. \& Davis, L. 2007. Exploring future competitive advantage through sustainable supply chains. International Journal of Physical Distribution and Logistics Management, 37(9): 763-74.

Mohr, J., Sengupta, S. \& Slater, S. 2010. Marketing of high technology products and innovations. Third Edition. Boston: Pearson Education Inc.

Moroke I. 2009. Seeking new meaning. Strategic Marketing, Issue 2: 3.

Peattie, K. 2001. Towards sustainability: The third age of green marketing. The Marketing Review, 2: 129-46.

Pesonen, H. 2001. Environmental management of value chains: Promoting life-cycle thinking in industrial networks. GMI, Spring 2001: 45-58.

Rogers, E. M. 2003. Diffusion of innovations. Fifth Edition, London: The Free Press.

Shiva, V. 2008. Soil not oil: climate change, peak oil and food insecurity. London: Zed Books.

Spence, C. 2005. Global warming: personal solutions for a healthy planet. New York: Palgrave Macmillan.

The Presidency. 2009. President Jacob Zuma to attend Climate Change talks in Copenhagen.

www.the presidency.gov.za/show.asp?include=president/pr/2009/pr.12061648.htm (accessed 6 December 2009).

Van Zyl, J. 2009. Seven examples of SA suffering financially. FINWEEK, 6 August 2009: 14.

Webster, K. 2001. The scope and structure of the food supply chain. In Eastham, J.F., Sharples, L. and Ball, S.D. (Ed) Food supply chain management: Issues for the hospitality and retail sectors. Great Britain: Elsevier Butterworth Heinemann.

Whitfield, B. 2009. A quick fix: government wants a new health system. It wants it quickly and you'll pay for it. FINWEEK, 17 September 2009: 16-19. 